\title{
Ubuntu: A countermeasure for challenges of child-rearing
}

\author{
Rev. Jacob Mokhutso - PhD Candidate \\ ORCID ID:0000-0002-1757-6829 \\ University of the Free State \\ Bloemfontein, South Africa \\ MokhutsoJ@ufs.ac.za \\ Doi: https://doi.org/10.46222/pharosjot.1033
}

\begin{abstract}
The research examines the contributions of the African Indigenous Knowledge System and, more precisely, the African traditional philosophy of community or Ubuntu as a countermeasure against the challenges of child-rearing in a changing society. The research contends that Ubuntu has a sagacity from which the world can learn lessons to combat the challenges of child-rearing in a changing society. Challenges named above are mainly due to society becoming more modernized, and individualistic thereby neglecting African ways of child rearing. This is the case with urbanization whereby many people move to urban places for economic prospects. Another challenge is that of family decay worldwide, where there's an increase in a number of single parenting due to a number of factors. Some of those factors are due to the high divorce rate, the death of a partner etc. The author argues that Ubuntu can contribute to offering helpful solutions to the challenges under study. The research utilises the secondary research or desk research methodology. The results show that Ubuntu is a likely good countermeasure against the myriad of challenges in child-rearing worldwide. The research concludes that the utilisation of this African philosophy may be extremely valuable in contributing supportively to the many challenges of childrearing faced by people worldwide.
\end{abstract}

Keywords: Ubuntu, African, Indigenous Knowledge System, philosophy, community.

\section{Introduction}

Ubuntu is essential for harmonious co-existence and sustainable development in a multicultural society such as South Africa (Venter, 2004:159). This was and continues to be a fact, even though the world has changed and continues to change. As Bochanczyk-Kupka and Peciak (2019) mention, the modern world is changing rapidly. The most significant factor of change has been globalisation, which has impacted on the entire globe. It should be noted that the impact of globalization varies in different parts of the world. Some parts of the world have experienced mainly the negative impact, whilst others have experienced the positive or both experiences. Therefore, it should be noted that globalisation cannot be negative, or positive. Every system in the world has its own shortfalls, the same applies with globalisation. Trask (2011:1) elaborates on the impact of globalisation, stating that, in our contemporary environment, globalisation, directly or indirectly, has affected and continues to affect family life through the strategies and programmes created by economic and social policies. Among other challenges that have 
emerged due to globalisation is the internationalisation of social problems, as issues that arise in one location become problematic in another. People move across different parts of the world for various reasons such as poverty, wars, famine, and environmental degradation (Dominelli, 2010:606). Such movement not only affects adults, but also impacts on families and child-rearing.

Trask (2011:1) explains that globalisation impacts on work-family issues, family poverty, and the social exclusion of certain groups such as the working poor, especially women in developing countries from mainstream societies. Trask (2011:1) further argues that, as we witness the widespread economic, political, and technological transformations brought about by globalisation, we need to consider which policy responses are fundamental and responsive to family well-being. Trask (2011:1) says this policy will ensure that we strengthen individuals' physical and psychological health and mitigate the conditions conducive to social unrest when people are vulnerable as well as economically and socially marginalised. Bochanczyk-Kupka and Peciak (2019:25) argue that another challenge currently facing society is that, over 250 years ago, a market system based on entrepreneurship innovation and a self-regulating mechanism began to spread during the Industrial Revolution. This system led to rapid economic and social development and to progress in civilisation, which contributed to enormous changes in people's quality of life in the economies that had implemented the system. Furthermore, BochanczykKupka and Peciak (2019:29) mention that the progress of globalisation processes has emphasised specific social and economic problems for the governments of well-developed countries. These include the rise in unemployment; ageing societies; the high cost of social security incurred by the state; economic instability and income stratification; fiscal policy that is unable to simultaneously guarantee the effectiveness and implementation of the state's objectives; a more expensive state versus richer, more powerful and more influential transnational corporations; deficiencies in the functioning and implementation of basic state tasks, and a need to adapt to rapidly changing internal and external conditions.

In addition, Rabe (2017:2) notes that, as more women enter the labour market, they are less available to provide "free" care work, thus postulating the "crisis in care" (Glenn, 2004:501). Rabe (2017:2) notes another change, that in the vast majority of Western countries, there is a transition from a dominant neolocal, nuclear, heteronormative family, with the male as the primary breadwinner in most of the families. In Western societies, the emancipation of women, the growing number of women in the labour market, increasing longevity, higher divorce rates, growing recognition for same-sex couples, and unmarried parents all contribute to a rising number of single-parent and single-person households, voluntary childlessness, same-sex families, and so forth (Weeks, 2005:405f). Rabe (2017:2) notes that the nuclear family, which can be briefly defined as a social unit made up of two parents and their children, a relatively new family setting in East Asian (Ochiai 2009) and many African and Latin American countries, where the nuclear family was never the dominant structure. In African countries, poverty, migrancy and illness such as the HIV pandemic have contributed to the present range of family and household configurations. Poorer households often pool resources together; hence, multi-generational and skip-generation households are common (Budlender \& Lund 2011; Makiwane, Gumede \& Molefi 2016; Morison, Lynch \& Macleod, 2016). South Africa is especially rich in family diversity; it is the only country in the world where both same-sex marriages and polygyny (as part of customary marriages) are legally recognised (Rabe, 2016b).

Trask (2011:2) states that the impact of globalisation is often downplayed politically, economically, and otherwise. A serious disadvantage of the mainstream focus on the purely economic effects and challenges of globalisation is that it ignores the social consequences of the process on 
families and communities, especially in Africa. Furthermore, Trask (2011:2) states that vulnerable individuals such as children and the elderly living in poverty, people with disabilities, and marginalised societies feel the effects of economic restructuring as the product of globalisation. While children and the elderly are often discussed as distinct groups, it is essential to note that both are usually reliant on their families and that the social capital provided by the family ensures their quality of life. Reducing or eliminating programmes such as nutrition, health, early care, educational opportunities, and lifelong disadvantages that have long-term social ramifications that affect families may be created. Lastly, according to Trask $(2011: 2,3)$, globalisation transmits new knowledge about gender, work, citizenship, identity, familial relationships, and women's and children's rights; even very distant places perceive globalisation as a form of enforced Westernisation. These are briefly the common challenges currently facing society, especially the family. Trask (2011:3) further mentions that globalisation has transformed the role of nation-states and families' ability to maintain and protect their members. Families are compelled to be more self-reliant in an environment where they may have fewer options. United Nations Children's Fund (hereafter, UNICEF) (2011) published a report that shares two main challenges for children. First, the Internet, mobile phones, and other technologies consume most of their time nowadays. In some instances, such gadgets raise the children and relate to them more than their parents do. For them, the distinction between online and offline has increasingly become meaningless, and they move seamlessly between both environments. Secondly, their coming-of-age, in this era of exponential innovation, has widened the generational divide between them and their parents, teachers, and other caregivers (UNICEF, 2011). These two challenges and many others not mentioned in this research have led to further challenges such as child pornography and child trafficking. Van der Watt (2020:64) notes that young girls as young as 11, 12 are held and exploited in brothels. Van der Watt $(2020: 2,3)$ further notes that about 30000 children under the age of 14 are trafficked into sex trade in South Africa annually. Research in this area of child pornography, prostitution, child pornography and trafficking argue go hand in hand. The Internet, mobile phones and other electronic media devices give children and young people access to information, culture, communication, and entertainment that was impossible to imagine twenty years ago. However, many of these extraordinary benefits come with some hazards (UNICEF, 2011).

Furthermore, UNICEF (2011) notes that, globally, children and young people tend to become early users and prime innovators on the Internet and are often far ahead of their parents and other adults regarding use, skills, and understanding. The Internet, particularly social networking and other interactive media, provides new forms of global social space that did not exist when the vast majority of contemporary parents were children. Nowadays, young people in all societies are pioneers, occupying online spaces in ways that adults often cannot imagine. This challenge has caused a divide between children and parents. However, globalisation, poverty, and capitalism have caused other challenges where children are neglected, due to economic challenges. The above is simply the tip of the iceberg. Society is changing drastically, due to the many challenges it faces and globalisation.

It should be noted that, when society changes, life in general changes and new challenges such as child-rearing also emerge. Some of the challenges of child-rearing are generalised in this chapter, due to globalisation because the world has become one big village. Among the big five challenges facing society is deterioration in family structure, redefinition of family, single parenting, death, and diseases. A solution to these challenges should be sought. This chapter suggests that, among the many solutions to this child-rearing challenge, Ubuntu can contribute immeasurably. Ubuntu is embraced throughout Africa; it is a philosophy at the centre of what makes African communities what they are. 


\section{Purpose}

The purpose of this research is to argue that Ubuntu's African philosophy has the sagacity from which the world can learn lessons to combat the challenges of child-rearing in a changing society. The author provides a more exhaustive definition of this philosophy and how it can contribute to child-rearing globally, before discussing the lessons that can be learned from these challenges.

\section{Significance}

This article argues that Ubuntu can contribute significantly as a countermeasure against childrearing in the world, even beyond the African continent. This research argues that this African philosophy may bring valuable contributions to the world can take lessons from to. Amos (2013:66) argues that African cultural values, as far as parenting is concerned, are being forgotten, and that the Western practice is adopted instead. This research seeks to contribute to this complex issue of child-rearing amidst the challenges faced by this $21^{\text {st }}$-century society. The following will be discussed in detail in this chapter:

- Defining child-rearing.

- African world view.

- An overview of African cosmology.

- The meaning of Ubuntu.

- The impact of globalisation.

- A re-construction of the death of Ubuntu.

- Individuality over community.

- Community as a mould.

- Fundamental principles of Ubuntu.

\section{Theoretical framework}

The social cognitive theory was chosen as a relevant theory to underpin this study. Social cognitive theory is the brainchild of Albert Bandura, known as the father of cognitive theory (Nabavi, 2014:21). Bandura (1989:21) defines this theory as follows: "Much social learning occurs either deliberately or inadvertently by observing the actual behaviour of others and the consequences for them. However, a great deal of information about behaviour patterns and the effects they have on the environment is gained from models portrayed symbolically through verbal or pictorial means". Nabavi (2014:4) mentions that this theory is based on the idea that we learn from our interactions with others in a social context. By observing the behaviour of others, people develop similar behaviours. After observing the behaviour of others, people assimilate and imitate that behaviour, especially if their observational experiences are positive or include rewards related to the observed behaviour.

\section{Defining child-rearing}

For Undiyaundeye (2014:2), child-rearing simply means parenting, a practice that differs from parent to parent and from culture to culture. According to George and Rajan (2012), child-rearing practices are a generalised term used to refer to distinctive ways of handling or dealing with one's 
children. Gadsden et. al (2016:1) defines this term as the process of bringing up a child from birth to adulthood. Child-rearing can depend significantly on cultural influences and how parents decide on such complex issues as whether the mother should work and adequately discipline a child. Scholars such as Stavrinides and Nikiforou (2013:60) have studied different styles of parenting and shares the following: Firstly, the authoritarian style of parenting, which mainly issues demands to children. In this style, parents set rules, and children are expected to obey those rules without any questions. A second style is called the authoritative style of parenting, this style scores high in demand and response, and can also be neglectful (Stavrinides \& Nikiforou, 2013:60). The third one is the permissive style, this style is explained as parents who are more responsive towards their children and have lower levels of demand. These parents believe that they should be on the same footing as their children (Mamaleka 2019:49). The fourth style is called uninvolved style of parenting, this refers to parents who do not pay much attention to their children's activities and display a low attitude in response and demand (Mamaleka, 2019:50).

\section{African world-view}

This section of the study explores African cosmology and the meaning of Ubuntu, with an overview of what informs and guides the African world view, especially the understanding of Ubuntu.

\section{An overview of African cosmology}

This section explores African cosmology that informs Ubuntu. To fully understand the African philosophy of Ubuntu, it is helpful to provide an overview of the nature of African cosmology, a topic that informs this philosophy of Ubuntu. Firstly, Udefi (2012:60) briefly defines cosmology as follows:

The term is derived from the Greek (Kosmos) meaning world and (Logos), discourse. Then it can be defined as the study of the origin, structure and development of the world or universe in its totality. Again, it can loosely be defined as that branch of metaphysics after ontology (the study of the meaning and nature of being), which treats the universe as an ordered system.

Udefi (2012:60) further defines cosmology as follows:

Both cosmology and myths are related since they attempt to address through narratives, the problems bordering on the origin and nature of the world, man and existence generally.

Anthony $(2013: 533,534)$ defines African cosmology as simply the way in which Africans perceive, conceive, and contemplate their universe; this refers to the lens through which they view reality that affects their value systems and behavioural orientations; it is the African's search for the meaning of life. Furthermore, Bujo (1992:17) mentions that African people, in their world view, do not distinguish between the biological and the physical, but instead they regard all life as constituting a single, undifferentiated whole. Bujo (1992:20) goes on to state that life for the African has a hierarchical ordering:

Life is a participation in God, but it is always mediated by standing above the recipient in the hierarchy of being. This hierarchy belongs to both the invisible and visible world. In the invisible world, the highest place is occupied by God, the source of life. Then the founding fathers of clans, 
who participate most fully in the life of God. Then come the tribal heroes, deceased elders, other dead members of the family, and various invisible beings, including earthly powers, although these belong partly to the visible world. They include the king, the queen-mother, and those who wield or represent the total power; the chiefs of the clans and the oldest members of families; heads of households; family members...Every member of a clan or family group is obliged to maintain contact with the dead and keep alive relationships with the living, whom the ancestors have established as their representatives (Bujo, 1992:20).

Bujo (1992:22) further states that, in the African world view, God, the ancestors and the elders, in their respective positions, take care to lay down rules in the form of laws and taboos to ensure the prosperity of society. When the descendants remained faithful to their inheritance and thus made the ancestor's experience their own, they remained in living communion with both the ancestors and their living kin, continually re-living the history of their people and proclaiming the marvels that their God performed for them. According to the African world view, a good deed enhances the community's health and helps develop the mystical body and evil deeds towards the destruction of the community. This notion can be questioned by many, especially when reflecting on the recent xenophobic attacks in South Africa. It should be noted that such xenophobic attacks should be understood as a reaction by many South Africans who are not benefiting from the richness of Africa's resources. Xenophobia is not African, but an act of desperation due to economic injustices majority Africans are subjected to by greedy and corrupt politicians. In the African world view, all things depend on each other. This applies particularly to human beings, as they are closely connected with God (Bujo, 1992:23). Bujo (1992:25) further mentions that the idea of communion with the dead is central to the Africans' world view simply because the ancestors are models for the living.

Therefore, African cosmology provides a necessary background of the origin of Ubuntu. It brings through the importance of harmony, which should exist between God, ancestors, human beings, and nature. The philosophy of Ubuntu stems out of this understanding.

\section{The meaning of Ubuntu}

It should be noted that the words 'philosophy of community' and 'Ubuntu philosophy' will be used interchangeably in this chapter. The philosophy of Ubuntu represents an African conception of human beings and their relationship with the community that embodies the ethics of defining Africans and their social behaviour (Khomba 2011:130). According to Idoniboye-Obu and Whetho (2013:230), Ubuntu or the philosophy of community is an African world view, doctrine, ideology, philosophy, ethic, community-based mindset, and culture. It is said to be the "basis of African communal cultural life'. Venter (2004:149) notes that Ubuntu promotes the common good of society and includes humanness as an essential element of human growth. Broodryk (1997:72) adds that Africans are group-oriented, and family relations are critical.

According to Shutte (2001:25), "[t]his is the insight that persons depend on persons to be persons, umuntu ngumuntu ngabantu. It is this insight that gives the African conception of community its distinctive character." Shutte (2001:21) adds:

In the traditional African view, the universe is not composed of things that interact with other things. Rather, it is seen as a world of forces interacting with other forces, a universal field or force. Everything that exists, such as stones, plants, animals, and persons, is the focus and expression of interacting forces. These forces are not seen, as in the materialistic view, 
as simply physical. They are also present in our emotions and ideas. But nor are they simply spiritual either. They are also present in our muscles and our blood.

Hence, Forster (2010:13) adds that some key characteristics of Ubuntu as reflecting the essential unity between self and others, as well as the self and the entire Kosmos, is a vitally important aspect in relating the African world view to an integrated approach to consciousness. Nussbaum (2003:2) mentions that Ubuntu is the capacity in African culture to express compassion, reciprocity, dignity, harmony, and humanity, in order to build and maintain the community with justice and mutual caring. This African philosophy of Ubuntu calls upon us to believe and feel that:

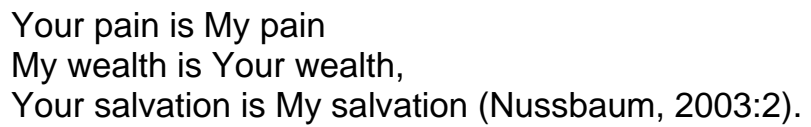

The African world view emphasises the survival of the family. It should be noted that for Africans it is not so much the survival of the individual that matters as that of the family, the clan, the ethnic group, and the entire ancestral group (Echekwube,1994:38). Nurnberger (2007:23) also observed that, in Africa, huts are round in shape, with a fireplace in the centre. It is in a hut where the family sits around the fire in a circle. The circle is the most fundamental expression of solidarity.

According to Msila (2008:67-70),

[a]s a worldview, Ubuntu is characterised by such basic values as humanness, caring, sharing, respect and compassion....warmth, empathy, giving, commitment and love...alms-giving, sympathy, care, sensitivity to the needs of others, respect, consideration, patience and kindness.

Kamwangamalu (1999:27) defines Ubuntu as:

[...] a value system that governs societies across the African continent. It is a system against whose values the members of a community measure their 'humanness'. Like the Ubuntu system from which they flow, these values are not innate but are rather acquired in society and are transmitted from one generation to another through oral genres such as fables, proverbs, myths, riddles, and story-telling.

Africans are social beings in constant communion in an environment where human beings are regarded as human beings only through their relationships with other human beings (cited Tutu in Battle, 1997:39-43). Therefore, the survival of a human being in an African perspective is dependent on other people - the community and society. Ubuntu transcends the confines of the nuclear family by including the extended family. As a philosophy, Ubuntu is an inclination to life that contrasts with rampant individualism, insensitive competitiveness, and unilateral decisionmaking. Venter (2004:149) mentions that, in African culture, the community always comes first. Therefore, an individual is born out of and into the community and will always be part of the community. Interdependence, communalism, sensitivity towards others, and caring for others are all aspects of Ubuntu as a philosophy of life (citing Le Roux, 2000:45).

Rational behaviour, as the person's ability to reason within the communal context, thus Ubuntu focuses on the positive human values such as love, sympathy, kindness, and sharing. The Ubuntu philosophy implies that one can only increase one's good fortune by sharing with other members of the society and enhancing their status within the local communities (Khomba, 2011:131). The African Ubuntu philosophy, is premised on community solidarity, it demands that an individual's 
success should not be antagonistically achieved at the expense of others, as the purpose of the group's existence is communal harmony and well-being (Khomba, 2011:131).

Idoniboye-Obu and Whetho (2013:229) state that, in the African community, there is an implicit and expected obligation of persons to the community, which gives them their identities. IdoniboyeObu and Whetho (2013:233) summarise this philosophy in the following manner:

Ubuntu is the capacity in African culture to express compassion, reciprocity, dignity, harmony, and humanity to build and maintain a community with justice and mutual caring. Ubuntu, a Nguni word from South Africa, speaks to our interconnectedness, common humanity, and the responsibility to each other that flows from our deeply felt connection. Ubuntu is conscious of our natural desire to affirm our fellow human beings and work and act towards each other with the communal good in the forefront of our minds.

Furthermore, this philosophy of community or Ubuntu is defined by its meaning and why it is embraced among African communities. Different scholars define this philosophy's characteristics and use it as an alternative philosophy or teaching tool in government policy matters, in the studies of management and leadership, financial management, as well as in peacekeeping efforts, and so on.

\title{
The impact of globalisation
}

Ogunbado (2012:51) states that colonialism is a phenomenon that continents such as Africa and Asia experienced from Europeans' significant powers. It is defined as exploiting a stronger or weaker country or using its resources to strengthen and enrich the stronger country. However, colonialism did more than simply exploit the resources of weaker countries. Ogunbado (2012:54) argues that colonialism had a positive and negative impact on Africa as well.

Ogunbado (2012:54) further mentions that the introduction of Western education caused several changes in the African way of life such as, among others, construction, transport, factories, and many other inventions that developed many parts of Africa and the world. According to Arowolo (2010:nn), globalisation, among other accompanying negatives, meant the undermining and subjugation of the African belief system.

\begin{abstract}
With Africa subjugated and dominated, the Western culture and European mode of civilisation began to thrive and outgrow African cultural heritage. Traditional African cultural practices paved the way for a foreign way of doing things as Africans became fully 'westernised'. Western culture now is regarded as a frontline civilisation (Arowolo, 2010:nn).
\end{abstract}

Furthermore, Ogunbado (2012:54) adds other negative aspects of colonisation that denigrate African belief systems and impose Western and Christian religions. Pricous (2010:1) states that no man is an island by themself. In the same logic applies, no nation is an island to itself. The same thought can be applied to Africa, its culture, philosophies, and traditions. As the world has become one big village, Africa, South Africa, to be precise, are also impacted. Pricous (2010:1) adds that there is an interaction of cultures in international interactions and, thus, a borrowing and diffusion of one culture over the other. This is true for globalisation that has generated much controversy regarding the rise of a global culture, in which Western norms and practices are gradually being transmitted globally as standard and acceptable behaviour. The hitherto cherished and dynamic African culture has been diluted, if not eclipsed. 
Broodryk $(2010: 28,29)$ shares that Germany, Italy, Portugal, France, Britain, Belgium, and Spain were the first European powers to be involved in the division of Africa. The African peasants were forced to accept foreign European cultures. Even European languages were forced down the throats of peace-loving local indigenous peoples. It should be noted that with many years of colonization in Africa, it has altered African modes of thought, patterns of cultural development, and ways of life forever. Actually, what the colonizers imposed on Africans in a long run became part and parcel of the Africans way of life such as languages of the colonizers which are still spoken in most parts of Africa (Settles \& McGaskey, 1996:n.p). In every part of the globe, in Asia and America, and now in Africa, local cultures are obliterated by a first-world cultural growth that spreads across the world wherever science and technology take it (Shutte, 2001:4, 5). Science and technology make this cultural colonisation possible through television, telephone, airwaves, and the Internet. Science and technology are also part of this spreading culture and have formed its character and soul.

According to Pricous (2020:1), globalisation has a political, economic, cultural, and even religious impact on individuals, nations, and the world. Such an influence does not take place through natural inheritance. It is not genetically transmitted. Instead, it takes place by absorption from the social environment or through deliberate instruction or the process of socialisation. If culture is learned, it can equally be unlearned. Africa has a great deal to unlearn (those Western values alien and destructive to African culture) from contact with the West (Pricous, 2010:2). Therefore, as much as they were learned, traditional African practices can be unlearned through the influence of globalisation.

Madukwe (2010:264) mentions that pre-colonial Africans had their peculiar culture, as evidenced in their ways of life. Their value systems, as elements of their culture, are depicted in marital relationships, communal living, religious practices, legal systems, and so on. However, with the exceptional contact with Western culture through colonialism and the subsequent upsurge of globalisation, these values are being challenged and eroded. Madukwe (2010:266) further argues that Westernisation cannot be dismissed from globalisation. It has been correctly assumed that, in some quarters, Western thought gave birth to globalisation, which propagates Western culture. Globalisation is derived from the word "globe", the world. Globalisation is a process whereby economies, societies, and cultures are integrated into a global network of communication and trade.

This is correct to the extent that colonialism serves as a vehicle of implantation of cultural imperialism in Africa. Colonialism, perceived in this context, is an imposition of foreign rule over indigenous traditional political setting and foreign dominance and subjugation of African people in all spheres of their social, political, cultural, economic and religious civilisations (Arowolo, 2010:n.p.).

Madukwe (2010:271) further notes that African communalism, supported by the extended family system, permeates every aspect of an African's life. Family in Africa is not understood like it is understood in other parts of the globe such as Europe, instead, for Africans family refers not only to the nuclear family setup, but it is inclusive of the extended family which includes uncles, aunts, grandparents, and cousins. That is how African's understands and view family. Westernisation and its attendant individualism have eroded this principle which presupposes equality for all and responsibility of all for one. With the creation of cities during the colonial era, family members were separated, and people were detached from their traditional, social, and cultural settings. Consequently, parental authority and established marital conations were weakened. The development of cities resulted in the influx of people from different ethnic groups, thus creating a heterogeneous society. 
Urbanisation introduced fundamental changes to values acceptable to its dwellers and gave rise to the individualisation of city life; a high premium was placed on money. Money now became everything. It became a symbol of status and social security. Writing about Western culture's impact on African society, Sibani (2018:57) states that African native culture gave way to European culture. Either by design or accident, Africans have imbibed the Western culture and have appropriated it so much so that it now becomes almost part and parcel of their lives. Anowolo (2010:2) states that Western culture is now regarded as a frontline civilisation. African ways of doing things became primitive, archaic, and regrettably unacceptable in the public domain. In this process of globalisation, the extended family that was an excellent mechanism like a social verve, social security in our community, has given way to the nuclear family (Anowolo, 2010:7).

\section{A re-construction or the death of Ubuntu?}

Van der Walt (2010:250) argues that, as a traditional tribal life view, Ubuntu could be updated or modernised in several ways. This supplements with time and with the change in society, what was understood as Ubuntu also changed. Scholars such as Rabe (2017:1) argue that changes in Ubuntu are due to African communities' challenges such as poverty, migrancy, and illness (such as the HIV pandemic) that have contributed to the present numerous family and household configurations. Among other challenges of communalism is the history of humanity that is replete with an 'admixture' of various forms of relationships. On the one hand, there is some form of suppression and repression of individual aspirations and capabilities in favour of the collective (Nnambi 2007:14). Van der Walt (2010:249) posits that something has happened to the African community and states that life in this part of the world has, for decades, been characterised by wars, violence, soaring crime rates, delinquent behaviour, subtle forms of sexism, xenophobia, selfishness, the collapse of family life, a growing gap between the rich and the poor, corruption, and racism. Such conditions are detrimental to the quality of personal and communal life. Other scholars such as Keevy (2009:21) argue that African law and religion cannot be separated and that Ubuntu is amongst the systems that entrenches patriarchy and discriminates against gay people (Kroeze, 2020:4).

However, it should be noted that, when society changes, some cultural practices and philosophies also change. Some die, and others thrive within the change happening in society. The same applies to the philosophy of Ubuntu. Cornell and Van Marle (2005:196) criticise Ubuntu as inherently patriarchal and conservative. Two well-known African scholars, Matolino and Kwindingwi (2013: 197) are critical of this African philosophy and argue that history has shown that narratives to promote Black identity have consistently failed. They also mention that Ubuntu cannot shape ethics. Among the other factors that have caused the changes in Ubuntu, the economy and urbanisation have led many people to migrate from villages to towns and cities for a better life and economic opportunities.

However, this does not mean that the principles of the Ubuntu philosophy should not be applied to teach or offer a helpful contribution to the challenges facing our modern society. This chapter argues that there are fundamental principles that can offer meaningful lessons to the modern society.

\section{Individualism over community}

Nnambi (2007:14) mentions that people with 'socio-centric' and 'organic' philosophical mindsets like to take an active interest in one another's affairs and feel at ease in regulating and being 
regulated by others. Such people will have no qualms in subordinating individual interests to those of the collectivity, making individuals mere appendages to the entity (community). Oliver et al. (2016:226), referring to the Igbo people, who have a similar set-up in many African societies, mention that these communities were the bedrock of existence in Africa. They lived together as descendants of common ancestors. The community was not simply a conglomeration of people living together in a particular space. Instead, it was a union of people living together in a shared space and sharing their lives.

Having said this, and having defined a set-up in African communities, individualism is frowned upon, because too many African societies for the Africans to be is to-be-with, and the purpose of existing, being-with, is to ensure a continuous enhancement of life and its optimal transmission (Oliver et al. 2016:226). Oliver et al. (2016:226) further posit that this communion gives this beingwith its meaning. The bottom line of this communal system is that the community is prioritised, because the community's needs supersede and are ranked above the individuals' needs. The individuals are the actors in the community (Oliver et al., 2016:226). Gyekye (2002:299) argues that, in the African world view, it is a fact that an individual human being is born into an existing human society and, therefore, into human culture, the latter being a product of the former. Gyekye $(2002: 299,300)$ further argues that a person born into an existing community must suggest a person's conception as a communitarian being by nature, even though some insist on individuality.

\section{Community as a moulder}

Gyekye (2002:300) argues that, according to the African understanding, a community includes the necessary relationships that complete the being of the person who, before entering into those relationships, would not be self-complete. As an Akan maxim reminds us, a person is not a palm tree that s/he should be self-complete or self-sufficient (on 'tpa nnye abe na ne ho ahyia ne ho). In the social context, in terms of functioning or flourishing in a human community, the person is not self-sufficient; his/her capacities, talents, and dispositions are not adequate to realise his/her potential and basic needs.

In contrast to Gyekyes (2002:300) mutually enhancing understanding and Shutte's idea that the community empowers and inculcates "personness", Nyasani (1997) has a far less egalitarian view of the individual in African society. Agulanna (2010:287) shares several benefits of belonging to a community. By 'community', on the other hand, we usually think of a sub-society whose members are in personal contact; are concerned for one another's welfare; are committed to everyday purposes and procedures; share responsibility for joint actions, and value membership in the community as an end worth pursuing (Kneller 1971:49). Agulanna (2010:288) further posits that community life helps create a sense of amity and security among the members of society. It also helps foster respect for each member of society. Amos (2013:69) argues that an extended family is a robust tool in parenting. It helps develop a strong sense of social responsibility in the child from the early years. The child learns to be a respectful, responsible, and supportive member of the extended family and society.

Despite the breakdown of the initial community within African communities, society still lives on among relatives, friends, religious communities, political affiliations, health communities, and educational communities, to mention a few. 


\section{What does Ubuntu mean to modern society?}

This study suggests that Ubuntu can teach modern society crucial parenting principles, despite a question posed by Stavrinides and Nikiforou (2013:59): Is there such a thing as "universal parenting" or do we always have to take into account culturally specific parenting practices and equally specific outcomes? Can Ubuntu be a universal philosophy? This study argues that it is. Shutte (2001) and Broodryk (2002) argue that Ubuntu should be exported to the rest of the world as Africa's gift to humanity. Nicolaides (2015) says that Ubuntu in a way controls the norms of conduct and criteria for achievement and is characterized by a strong sense of communal life, which articulates itself in a rather difficult set of linkages in social relationships. The same author argues that Ubuntu is important in all spheres of life (Nicolaides, 2014), including the workplace and public service (Nicolaides \& Manyama, 2020). It then also teaches society other important principles through which to co-exist with others in harmony..

The authors mentioned the African philosophy of Ubuntu and the fact that, due to changes in society, it has also evolved, but remains relevant in contributing effectively to modern society. Besides this philosophy as means of contributing to challenges in child-rearing, Eliastam (2015:2) adds that the principle of Ubuntu resonates with universal values of human worth and dignity.

\section{Fundamental principles of Ubuntu}

The Sesotho/Tswana translation Motho ke motho ka batho (I am because I belong). Bessler (2008:33) adds that this means the essence of being human. Eliastam (2015:2) defines Ubuntu as meaning that a person is a person through other people or as translated in Nguni languages in South Africa (Umuntu ungumntu ngabantu). The understanding is not, I think therefore I am. Instead, I am human because I belong. Trask (2011:1) argues that an interrelated, coordinated set of universal social programmes available to all their respective societies can strengthen families. This Ubuntu principle emphasises the fact that parents alone cannot effectively raise their children; they need others to assist them.

In elaborating on the meaning of an African approach to child-rearing, Healey (1998:1) states that it takes an entire village to raise a child. The saying primarily means that child upbringing is a communal effort. Raising a child is shared with the more prominent family (sometimes called the extended family). Everyone becomes involved, the older children, aunts and uncles, grandparents, and even cousins. It is not unusual for African children to stay with their grandparents, aunts, or uncles for long periods (Healy 1998:1). The beauty of this child-rearing approach is that a parent/s has/have support.

This is more important especially with new parents, and single parents, this parenting approach means there are other helping hands in this journey of parenting. This is the case even in our modern society, society is communal although different from the African worldview. Parents need to develop strong relationships with their children's teachers at school so that they can succeed in their education. Parents need to build a strong relationship with their family doctors for the excellent health of their children. The same applies to religious institutions, political affiliation, employees union, recreational and social institutions. This is the norm, despite the individualist lifestyle society has embraced; still, all people belong to a community. The community is no longer that small African village of old. The community can be one's neighbourhood, a workplace, a social club, and so on. In belonging to these different communities, one learns, relearn, grow, and prosper in many aspects of life. 
In these communities, different characters mould, teach, annoy us, but in the process they mould our character. Hence, according to Stavrinides and Nikiforou (2013:66), some studies found that parental involvement is associated with multiple positive consequences. According to Georgiou and Christou (2000), parental involvement is associated with children's development of positive self-esteem. People who genuinely practice Ubuntu are always open and make themselves available; they affirm others and do not feel threatened by those who are able and good. Ubuntu assures us of the fundamental recognition that everyone belongs to a greater community.

\section{It takes a village to raise a child}

It is in the spirit of Ubuntu that African people believe that it takes an entire village to raise a child. A child is born into a community whose responsibility is to raise and nurture. Gambardella (2009:1) notes that a child needs stable and secure relationships and bonding in order to thrive. Healey (1998:1) elaborates on the meaning of this African proverb. There are different forms of this Igbo and Yoruba (Nigeria) proverb in many African languages. If the definition of Gadsden et.al (2016:19), is embraced, it is in line with Africans believe when saying that " parenting often is defined as a primary mechanism of socialization, that is, a primary means of training and preparing children to meet the demands of their environments and take advantage of opportunities within those environments". The basic meaning is that child-rearing is a communal effort shared with the more prominent family (sometimes called the extended family). Everyone participates, especially the older children, aunts and uncles, grandparents, and even cousins. It is not unusual for African children to stay with their grandparents or aunts, or uncles for long periods. Even neighbours and friends get involved. Children are understood to be a blessing from God for the entire community (Larkhall's Children, 2014:1). In their homes, children first learn to socialise; on their way to the shops, they first come to realise that not everyone thinks or behaves like their parents, and in school, they learn to connect all that and steadily flex their mental powers. It is within a group, or when interacting with others whether at home, school, work, or areas we live in that we learn about our own character, talents, and weaknesses as well. Psychology scholars attest to this African proverb, stating that, from the social cognitive perspective, social factors play a key role in the cognitive development, and there are many motivators of the pursuit of competence. Maturational factors and the information gained from exploratory experiences contribute to cognitive growth (Bandura, 1989:12). However, the most valuable knowledge is imparted socially (Bandura, 1989:12). Forster (2010:13) elaborates that the importance of the ethics of 'ubuntu' in shaping identity in traditional African societies cannot be underestimated.

\section{Compassion}

Among many things that this African philosophy Ubuntu teaches is compassion, a trait that all parents' wishes for their children to emulate. Amos (2013:69) gives an interesting example to elaborate on this point when saying; My parents were so poor that my mum's brother or father's sister helped towards my education or that my father's brother trained me to read medicine, law or pharmacy and that my in-laws gave me money to go into business. This spirit of Ubuntu teaches a person the value of caring for others. It is within a group that one learns how it feels to be valued, loved, and cared for, thereby imparting that to an individual to value others.

It must be noted that many local teachers, doctors, chiefs, priests, shop owners have assisted many young people in African communities with applying for bursaries because their families didn't have anyone who would read or write, with tuition fees, clothing, furniture, and many other 
amenities they needed. Such practices are a characterization of many growing up seeing their families being compassionate to others. Amos (2013:68) further adds the important role the extended family plays, when saying that it is a cohesive unit which ideally provides economic, social and psychological security to all its members. Such practices for many emanate from having experienced the same from a cousin who shared their school books and uniform when they moved to a higher grade, clothing when they outgrew them, a toy when they had a new one or had more toys. This is not only something that exists within a household or blood relatives, but it is also communal. It happens when there's a funeral, women in the community would take their knives to go to the bereaved home to assist with pilling vegetables, cooking, and being amongst the bereaved for support. Men would assist with digging a graveyard, even filling it during the time of the funeral. Men would assist in slaughtering the cow, which is normally cooked, and assist women too with carrying heavy equipment's etc. Ubuntu not only teaches the little ones, but also permeates all spheres of the community. Such is what is learned from Ubuntu, compassion, to see a God created being when looking and relating to the other.

\section{Safety and support}

Within a community, a person feels safe and supported. The safety aspect of Ubuntu is that ubuntu recognises a person's status as a human being, entitled to unconditional respect, dignity, value, and acceptance from the members of the community of which a person happens to be part (In the spirit of Ubuntu, 88, 89). It is within the community where one is exposed and interacts with people who have different years of parenting children, children with different characters, of different ages, and abilities. It is within this community that parents find abundant support from this pool of experience of different parents. It is a community where they feel free to seek help and make mistakes, knowing that there's someone who will come to their rescue. According to Healey (1998:1), in general, this Nigerian proverb It takes a village to raise a child; conveys the African world view that emphasises the values of family relationships, such as parental care, selfsacrificing concern for others, sharing, and even hospitality. Bessler (2008:33) posits that Ubuntu recognises that my humanity is bound up in yours, for we can only be human together. Msengana (2006:89) mentions that African cultural practices of the principles of Ubuntu depend on tightly woven interpersonal relationships. The individuality of any person with the community culture or way of life is discarded. In this relationship, the community takes preference over the individual who is, in turn, cared for and protected by the community. Gadsden et.al (2016:19) adds that attachment security is a central aspect of development that has been defined as a child's sense of confidence that the caregiver is there to meet his or her needs (citing Main and Cassidy, 1988). Therefore Ubuntu ensures that this security, protection and sense of care is always available to not only the child/ren but for the parents too knowing that help is always within reach.

\section{Inspiration}

A person is inspired to do good by the community. Doing bad may result in one being exclude from the group. In African communities, there are ways in which one is expected to relate to God, ancestors, and others. That is expressed through language as well. There are ways in which men relate to women, and vice versa, children to the elders and vice versa. Anything else outside of the norm is not acceptable. Therefore, a person would always aspire to do the good taught and has seen lived by the community. In a community set-up, there are different individuals with different skills and strengths (Molefe, 2020:11). It is within the group where one is challenged to 
discover their own gifts and strengths. Ubuntu is thus a philosophy that aspires to inspire goodwill in others. This is what contemporary society needs amidst its many social ills (Gyekye, 2010:3).

\section{Help}

Child-rearing can be challenging, especially to parents in the $21^{\text {st }}$ century where both parents are generally working, who wants to pursue careers. This applies as well to single parents, who often do not have a helping hand, and are also faced with career, business prospects etc. In contemporary society, many challenges have made parenting very difficult. The family structure has changed, and many challenges faced by modern society can be eradicated within a community set-up. With Ubuntu, help is imminent; a person does not have to struggle alone; there is a neighbour, friend, an aunt, an uncle, grandparents, and so on. According to Bessler (2008:33), Ubuntu speaks about humaneness, gentleness, hospitality, putting yourself out on behalf of others, being vulnerable. It embraces compassion and toughness. It is within a group, a community where one finds the above. Lastly, Vivian (2016:386) adds that parents with knowledge of child development compared with parents without such knowledge have higherquality interactions with their young children and are more likely to engage in parenting practices associated with children's healthy development.

\section{Ubuntu's contribution to child-rearing}

Ubuntu emphasises that there is no single person who has or is $100 \%$ in everything by themselves. This refers to skills, and all other human qualities, education, and religious background. There will always be an area where a person lacks and needs the skills and wisdom of others. Venter (2004:151) highlighted that an African person is an integral part of society. It does not matter how good a person may be. Others are needed, to make a person $100 \%$ or whole.

Family, siblings, friends, neighbours, colleagues, as well as other sectors in our society such as the religious, health, education, economic, political, social, recreational, and the entertainment sectors all have something to contribute to a person's life. A person becomes stronger, wiser, experienced, spiritual, religious when belonging to a community that would contribute that in their lives. This applies to the challenges society faces in child-rearing. According to Gyekye (2002:297), a social structure is an outstanding, necessary feature of every human society. It gives effect to conceptions of human nature and provides a framework for realising the potentials, goals, and hopes of the individual members of society and the continued existence and survival of society (Agulanna, 2000:289). The relevance of the above to the present discussion is to restate a point made earlier: Human beings need the anodyne of society or community, to live a life of self-achievement. According to Venter (2004:159), some authors view Ubuntu purely as a local concept, but most of the elements of Ubuntu or the values that underpin Ubuntu are also universal (Sindane \& Liebenberg, 2000). In elaborating on this point, Bell and Metz (2012:85) says that a similar philosophy exists amongst the Chinese or "Confucian" where during a time of conflict mediation is preferred in order to restore harmonious relations, which is crucial. Communal harmony, health and wellbeing is central said to be central in Confucian philosophy. Bell and Metz (2012:82) adds that, just like Ubuntu, Confucianism values social ways of life above all else. Wong (2011:72) says the central belief of this philosophy is the belief in the oneness of heaven and humanity, and that relationship remains in harmony through harmonious existence not confrontation. In western perspective, individualism is embraced, a person is encouraged to expand their individual skills, and knowledge compared to the African and Asian perspectives. Webner and Abrahamson (2004:4) further says this is more than a Western philosophy, but 
modernity, which is characterised by choices which previous generations did not have. Although Ubuntu means African humanism, it shares values with humanity, in general. Values such as respect, dignity, empathy, co-operation, and harmony between members of society are not exclusively African, but they comprise the human race as a whole (Eygelaar, 1998). This remains ideal because, in the global village, it is not often practised, but the ideal would be that the human race care for one another. The philosophy of Ubuntu is encapsulated in most of the philosophies of life, although it is articulated and actualised in different ways.

\section{Conclusion(s)}

This article argued that Ubuntu can bring and contribute helpful contributions to the challenges under study. The study utilised a secondary source research method, sourced through document reviews. Its results showed that the African philosophy of community, or Ubuntu, if adopted by all of society it can most likely contribute as a useful countermeasure against the many challenges of child-rearing. It concludes that the utilisation of this African philosophy may be a helpful resource in remedying the challenges faced by society. This article gave an overview of African cosmology, as the origin of Ubuntu. The meaning of Ubuntu was defined, and different views which argue that Ubuntu is dead were explored. Individuality over community in the African perspective was also explored to an extent. Different themes contributed to this argument: community is the moulder; different characteristics of Ubuntu are proposed as possible contributors to the challenges in child-rearing. This research has argued that these principles can make an immense contribution amidst the challenges facing society today, if they are applied in all spheres, especially in assisting parents in child-rearing which is always a daunting task.

\section{References}

Agulanna, C. (2010). Community and Human well-being in an African culture. In Trames: Journal of the Humanities \& Social Sciences, 14 (64/59), 282 - 298.

Amos, P.M. (2013). Parenting and culture - Evidence from some African communities. In M. L. Seidl-de-Moura [Ed], Parenting in South American and African contexts (pp. 65 - 76). London,: IntechOpen.[Available online at https://doi.org/10.5772/56967].

Bandura, A. (1989). Social cognitive theory, In R. Varta (Ed), Annals of child development, 6. 'Six theories of child development', pp $1-60$.

Bandura, A. (2001). Social Cognitive Theory: An Agentic perspective. Annual Review of Psychology, 52, 1 - 26. [Available online at https://doi.org/10.1146/annurev.psych.52.1.1].

Bell, D.A. and Metz, T. (2011). Confucianism and Ubuntu: Reflections on a Dialogue between Chinese and African Traditions. Journal of Chinese Philosophy 39.supp.1:78 - 95.

Bessler, J.D. (2008). In the spirit of Ubuntu: Enforcing the rights of orphans and vulnerable children affected by HIV/AIDS in South Africa. Hastings International and Comparative Law Review, 31(1), 33 - 113. 
Bochannczyk - Kupka, D. Peciak, R. (2019). Some reflections on the new challenges facing the mordern state, ARGUMENTA OECONOMICA CRACOVIENSIA, 1(20) 33 - 37.

Broodryk, J. (2002). Ubuntu: Life lessons from Africa, Pretoria: Ubuntu school of Philosophy.

Broodryk, J. (2010). Africa is best, uBuntu school of Philosophy: Pretoria, Waterkloof.

Buddlender, D., \& Lund, F. (2011). South Africa: A legacy of family disruption. Development and change, 42(4) $925-946$.

Cornell, D. \& van Marle, K. (2005). Exploring ubuntu: Tentative Reflections, AHRLJ 195 - 220.

Dominelli, L. (2010). Globalization, contemporary challenges and social work practice. International social work, 53(5), 599 - 612.

Echekwube, A.O. (1994). An Introduction to African philosophy, Ibadan, Oyo State, Nigeria: Kraft Books.

Elistann, J.L.B. (2015). Exploring ubuntu discourse in South Africa: Loss, Liminality, and hope, Verbum et Ecclesia, 36(2).

Forster, D.A., (2010). A generous ontology: Identity as a process of intersubjective discovery An African theological contribution, HTS Teologiese Studies/ Theological Studies, 66(1), DOI: 10.4102/hts.v66i1.731

George, S. \& Rajan, A. (2012). Factors of child-rearing Practices: A Qualitative analysis, Journal of Psychology, 3(2), $99-105$.

Gyekye, K. (2002). Person and community in African thought, Oxford: University Press.

Gyekye, K. 2010. African ethics. The Stanford Encyclopedia of Philosophy. Edited by E.N. Zalta. [Available Online http://plato.stanford.edu/archives/fall2011/entries/african-ethics].

Healey, J.G. (1998). It takes a whole village to raise a child: African Proverb of the month. [Available Online https://whadamsfoundation.org/uploads/3/4/7/734772339/takes_village_afproverb.pdf]

Idoniboye-Obu. S. \& Whetho A. (2013). Ubuntu: 'You are becassue I am' or 'I am because you are'? Alternation: International Journal of Interdisciplinary Research in Arts and Humanities. 20(1), 229-247.

Kanu, I.A. (2013). The dimensions of African cosmology, Filosofia Theoretica: Journal of African Philosophy, culture and Religions, 2(2), 391 - 407. 
Keevy, I, (2009). Ubuntu versus the core values of the South African Constitution. Journal for Juridical Science, 34(2), 19 - 58

Khumbu, J. K. (2011), Redesigning the balanced scorecard model : an African perspective, PhD thesis, University of Pretoria, Pretoria.

Kneller, G. F. (Ed.). (1971). The impact of culture. In Foundations of education. In Foundations of education, New York: Wiley and Sons, Inc.

Kroeze, I. J. (2020). Once more uBuntu: A reply to Radebe and Phooko, PER: Potchefstroomse Eletroniese Regsblad, 23(1), 1 - 22.

Lassiter, J. E. (2000). African culture and personality: Bad social science, effective social activism, or a call to reinvent ethnology? African Studies Quarterly, 3(3), 1-21.

LeMarquand G. (1993). African Theology in Its Social Context Benezet Bujo New York: Orbis Books; Nairobi: Daughters of St. Paul, 1992. 143 p. Studies in Religion/Sciences Religieuses,22(3), 393393. doi:10.1177/000842989302200323

Madueke, C. I. \& Madukwe, H. N. (2010). African value system and the impact of westernization: A critical Analysis, International journal of Research in Arts and Social Sciences, $2,264-274$.

Mamaleka, M.M. (2019). Developing Guidelines for indigenous parenting practices: A case study of Makhuduthamaga Municipality at Sekhukhune District, Limpopo Province, South Africa.

Matolino, B. \& Kwindingwi, W. (2013). The end of Ubuntu, South African Journal of Philosophy, 32(2), $197-205$.

Msengana, N, W, (2006). The significance of the concept 'ubuntu' for educational management and leadership during democratic transformation in South Africa. PhD Dissertation. University of Stellenbosch: Stellenbosch Cape Town.

Molefe, M. 2020b. "Solving the Conundrum of African Philosophy Through Personhood: The Individual or Community?" Journal of Value Inquiry 54 (1): 41-57. doi:10.1007/ s10790-01909683-8

Msila, V. (2008). Ubuntu and school Leadership, Journal of Education, 44 (1), 67 - 84.

Nabavi, R.T. (2012). Bandura's Social Learning Theory \& Social Cognitive Learning theory. Theory of Developmental Psychology, $1-24$.

Nakano Glenn Evelyn, Creating a Caring Society, Cahiers du Genre, 2016/3 (HS No 4), p. 199224. DOI: 10.3917/cdge.hs04.0199. [Available online at https://www.cairn-int.info/journalcahiers-du-genre-2016-3-page-199.htm]. 
Nicolaides, A. \& Manyama, T. (2020). Eradicating Corruption in Public Service Entities through Ethical Leadership, Athens Journal of Law, 6(4), October 2020, 431-452

Nicolaides, A. (2015). Gender Equity, Ethics and Feminism: Assumptions of an African Ubuntu Oriented Society, Journal of Social Sciences, 42(3), 191-210.

Nicolaides, A. (2014). Utilizing Ubuntu to Inform Chief Executive Officer (CEO) Thinking on Corporate Social Responsibility (CSR) and Codes of Ethics in Business, Journal of Social Sciences, 41(1), 17-25.Nnambi, O.C. (2007). The Individual in African communalism. International Journal for Philosophy of Religion, 23(1), $13-27$.

Nurnberger, K. (2007). The Living dead and the living God, CB Powell Bible Centre, Pretoria,

Nussbaum, B. (2003). African Culture and Ubuntu: Reflections of a South African in America, World Business Academy, 17(1). 1 - 12.

Nyasani, J.M. (1997). The African psyche. Nairobi: University of Nairobi and Theological Printing Press Ltd.

Ochiai, E. (2009). Care diamonds and welfare regimes in East and Southeast Asian societies: Bridging family and welfare sociology. International Journal of Japanese Sociology, 18(1) 60 78.

Ogunbado, A.F. (2012). Impacts of Colonialism on Religions: An Experience of South-Western Nigeria, Journal of Humanities and Social Science, 5(6) 51 - 57.

Oliver, O., Hyginus, E. \& Theodora, O. (2016). The place of the individual in the Traditional sciences and Humanities, Journal of Sciences and Humanities Reviews, 6(3) 225 - 229.

Precious, O.U. (2010). Globalization and the future of African culture, Philosophical Papers and Reviews, 2(1), $1-8$.

Rabe, M. (2017). It takes a village to raise a child, but the village is ruined. Care and family policy in South Arica. Inaugural Lecture, June 2017. Pretoria: UNISA [Available Online http://uir.unisa.ac.za/bitstream/handle/10500/23081/Rabe\%20M_Family\%20policy_final_copies _ June\%202017.pdf?sequence=1\&isAllowed=y 83. Rabe].

Settles, J.D. \& McGaskey, F. (1996). The Impact of colonialism on African Economic development. Chancellor's Honors Program Projects. [Available Online https://trace.tennessee.edu/utk_chanhonoproj/182]

Stavvinides, P. \& Nikiforou, M. (2013). Parenting challenges, Practices and cultural Influences. In Parenting, (Eds). Barbies, P. Petrakis, S.,. Nowa Science Publishers, Inc. Cyprus. 
Shutte, A. (2001). Ubuntu: An Ethic for a new South Africa, Cluster Publications:

Pietermaritzburg.

Sibani, C.M. (2018). Impact of Wester culture on traditional African society: Problems and Prospects, International Journal of Religion ad Human Relations, 10(1), 56 - 72.

Trask, B. S.. (2011). Globalization and families: Meeting the family policy challenge. Expert Group Meeting on Assessing Family Policies: Confronting family poverty and social exclusion \& ensuring work family balance, United Nations Department of Economic and Social Affairs, Division for Social Policy and Development, United Nations, New York, NY.

Udefi, A. (2012). Philosophy, mythology and African cosmological System, Global Journal of Human-Social Science Research, 12(10), 59 - 64.

(2011). Child Safety Online: Global Challenges and strategies. Publication series: Innocenti Publications. van der Walt, J. L. (2010). Ubuntugogy for the $21^{\text {st }}$ Century, Journal of Third World Studies, 27, $249-266$.

van der Watt, M. (2020). Child trafficking and children in South Africa's sex trade: Evidence, undercounting and obfuscations. Child Abuse Research: A South African Journal, 2(1), 58 - 82.

Venter, E. (2004). The notion of Ubuntu and communalism in African Educational Discourse,Studies in Philosophy and Education 23, 149 - 160.

Vivian, L. G., Morgan. F, \& Heather. B. (Editors). (2016). Parenting Matters: Supporting Parents of Children Ages 0-8, National Academies of Sciences, Engineering, and Medicine, Washington, DC: The National Academies Press. Doi: 10.17226/21868

Webner, C. \& Abrahamson, P. (2004). Individualisation of family life and family discourses. Paper presented at ESPAnet conference, Oxford, September 9 - 11. [Available Online http://www.spsw.ox.ac.uk/fileadmin/static/Espanet/espanet conference/papers/ppr.10C.PA.pdf.pdf]

Rabe, M. (2017). It takes a village to raise a child, but the village is ruined. Care and family policy in South Arica. Inaugural Lecture, June 2017. Pretoria: UNISA

Weeks, J.R. (2005). Population. An introduction to concepts and issues, Ninth Edition (9 ${ }^{\text {th }}$ Ed). Belmont CA: Wordsworth.

Wong, P.H. (2012). Dao, harmony and personhood: towards a Confucian ethics of technology, Philosophy and Technology, 25(1), 67-86. 